\title{
Cara a Times Square ou o itinerario cara á negación da identidade
}

\section{Cara a Times Square or the path to the rejection of identity}

\author{
Beatriz Galiano LeIS \\ Università degli Studi di Roma "La Sapienza" \\ Centro de Estudos Galegos de Roma \\ begaliano@hotmail.com \\ [recibido 03/02/2013, aceptado 12/09/2013]
}

\section{RESUMO}

O propósito deste traballo é realizar un achegamento ao tratamento do tema da identidade, tanto dende unha perspectiva persoal como nacional, na novela Cara a Times Square. Con este fin, a atención póusase en tres aspectos fundamentais: a anonimia dos personaxes, o recurso a grandes espazos urbanos e a recorrencia do tema da estranxeiría.

Palabras Chave: literatura galega, Nova Narrativa Galega, Cara a Times Square, Camilo González Suárez-Llanos, Camilo Gonsar, identidade, identidade persoal, identidade nacional.

Galiano Leis, B. (2013): “Cara a Times Square ou o itinerario cara a negación da identidade”, Madrygal (Madr.), 16: 43-51.

\section{RESUMEN}

El propósito de este trabajo es realizar una aproximación al tratamiento del tema de la identidad, tanto desde una perspectiva personal como nacional, en la novela Cara a Times Square. Con este fin, se presta atención a tres aspectos fundamentales: la anonimia de los personajes, el recurso a grandes espacios urbanos y la recurrencia del tema de la extranjería.

PaLABRAS Clave: literatura gallega, Nova Narrativa Galega, Cara a Times Square, Camilo González Suárez-Llanos, Camilo Gonsar, identidad, identidad personal, identidad nacional.

Galiano Leis, B. (2013): “Cara a Times Square o el itinerario hacia la negación de la identidad”, Madrygal (Madr.), 16: 43-51.

\section{ABSTRACT}

This paper is an approach to the topic of identity throw a personal and a national perspective in the novel Cara a Times Square. With this aim, the attention settles in three fundamental aspects: the anonymity of the characters, the use of great urban spaces and the recurrent subject matter of immigration.

KEY wORDS: Galician Literature, Nova Narrativa Galega, Cara a Times Square, Camilo González Suárez-Llanos, Camilo

Gonsar, identity, personal identity, national identity.

GaLiano Leis, B. (2013): “Cara a Times Square or the path to the rejection of identity”, Madrygal (Madr.), 16: 43-51.

SUMARIO: 1. Introdución. 2. Estrutura e argumento da novela. 3. A anonimia dos personaxes. 4. A perda da identidade na grande urbe. 5. O protagonismo do tema da estranxeiría. 6. Peche. 7. Referencias bibliográficas. 


\section{INTRODUCIÓN}

En 1980 Camilo González Suárez-Llanos, Camilo Gonsar, publica Cara a Times Square, o terceiro dos catro títulos que compoñen a súa obra narrativa. Con anterioridade viran a luz os volumes Lonxe de nós e dentro (1961), colección de relatos que constitúe a súa primeira publicación (reeditada e ampliada en 1985 co título Lonxe de nós e dentro e outras páxinas), e Como calquera outro día (1962), novela construída a xeito de aproximación biográfica aos autores da Nova Narrativa e ao seu ambiente de formación ${ }^{1}$. A produción narrativa do autor completarase en 1983 coa aparición da novela Desfeita.

A propósito da etiqueta estético-xeracional que vimos de utilizar, cómpre sinalar que non existe acordo entre os estudosos respecto da inclusión da novela obxecto deste traballo, Cara a Times Square, dentro da nómina de títulos que integrarían o movemento da Nova Narrativa Galega. Así, fronte a autores como Manuel Forcadela, que no seu manual (1993) a considera como constituínte dese macro-texto que ao seu ver constitúe a Nova Narrativa, se ben situándoa na última das tres fases que distingue para o decorrer do movemento ("fase de formación", "fase de auxe", "fase de liquidación"), outros autores, como é o caso de Camino Noia (1992), manexan criterios moito máis reducionistas, entendendo por Nova Narrativa Galega unicamente os textos comprendidos entre Nasce un árbore (1954) de Gonzalo Rodríguez Mourullo e a novela Cambio en tres (1969) de Carlos Casares. Posicionamento semellante mantén Dolores Vilavedra (1999), quen fixa os lindes cronolóxicos do movemento nas décadas dos anos 50 e 60, indicando que:

Pola nosa banda, e sen negar a herdanza técnica e temática da Nova Narrativa Galega en obras como Elipsis e outras sombras (1974) de X. L. Méndez Ferrín ou a xa citada Cara a Times Square, coidamos que estas son -como veremos- susceptibles doutra localización na cronoloxía literaria galega". (Vilavedra 1999: 255-256)

Non figura entre os propósitos destas liñas o de contribuír ao alicerzamento dunha ou outra tese nin a súa natureza esixe da autora a adscrición a ningunha delas; pola contra, constitúe esta unha cuestión irrelevante de cara aos obxectivos do presente traballo, razón pola cal nos limitaremos a manexar uns presupostos mínimos, isto é, a evidencia de que a obra de $\mathrm{Ca}$ milo Gonsar, canto menos, responde a boa parte dos criterios estéticos e temáticos comunmente manexados para caracterizar a nómina de textos que constitúen o movemento coñecido como Nova Narrativa Galega.

Certamente, serían numerosos os trazos renovadores susceptibles de citar neste sentido; porén, desta volta pousaremos a nosa atención unicamente sobre dous deles por consideralos estreitamente vencellados ao tema central da nosa exposición, mesmo basilares, tomando como tal tema central o asunto da identidade dos personaxes, tanto dende unha perspectiva persoal como nacional.

Os dous trazos aos que faciamos alusión son, por unha banda, a anonimia dos personaxes, dos que, como veremos, se omite deliberadamente o nome e practicamente toda información; pola outra, a presenza de grandes espazos urbanos, recurso este que contribúe a potenciar o primeiro e actúa esluíndo as identidades.

Finalmente, e tamén en relación coas cuestións anteriores e, por extensión, co asunto central do traballo, prestaremos atención a un aspecto de especial protagonismo na novela: o tema do estranxeiro e da estranxeiría, recorrente, como quedará de manifesto, en distintas formas e voces ao longo das súas páxinas.

Con todo, antes de mergullármonos na análise destas cuestións, e atendendo ás peculiaridades dunha historia de natureza ambigüa e desconcertante, consideramos de utilidade, para

\footnotetext{
${ }^{1}$ O prólogo da segunda edición de Como calquera outro día ábrese coa seguinte reflexión do autor: "Dixen que non estou fixo de que este libro sexa unha novela. Eu quixen reflexar certos aspectos do espírito de determinados membros dunha xeración. Demasiados xenitivos para unha frase baleira. Poñamos logo, tratando de concretar un pouco máis, que o meu propósito foi narrar un certo xeito de pasa-la Guerra Fría da década dos cincuenta".
} 
a mellor comprensión do exposto en apartados posteriores, ofrecer un breve esbozo do argumento e a estrutura da obra.

\section{ESTRUTURA E ARGUMENTO DA NO- VELA}

A novela bota man do recurso do manuscrito achado. Deste xeito, o texto ábrese cunha "Nota do traductor" na que este nos informa do feito de ter atopado un manuscrito redactado nun "pobre e incorrecto inglés", que el se encarga de traducir e que constitúe o conxunto da novela. Ao tempo que afirma descoñecer a identidade do autor e non ser o destinatario do manuscrito, o tradutor establece un distanciamento coa historia da que asegura ser mero transmisor observando que "non só non estou conforme coa maioría das ideas expresadas no relato, senón que me parecen simplemente repelentes".

Tras esta breve advertencia preliminar preséntase o corpo da novela, que aparece estruturada inicialmente en catro capítulos subdivididos en fragmentos numerados, aos que se engade posteriormente un quinto, titulado "Un epílogo desde fóra", que foi publicado no número 87 da Revista Grial.

O primeiro capítulo arrinca co anuncio do inicio do relato por parte do narrador. Despois de pasar a tarde bebendo whisky en diferentes bares dun barrio de Nova York cun vello inmigrante amigo seu, este, con súpeta présa, asegura ter que marchar, e o narrador comeza un deambular nocturno e solitario polas rúas case desertas da cidade. Detense, á fin, diante do que, segundo lle parece, podería ser unha parada de autobús e decide agardar, aínda que, en atención á hora, con escasa esperanza de que continúen a pasar autobuses polo lugar. Aparece outro camiñante, ao que a partir de entón o narrador se referirá como "o Belga". Este aconséllalle suspender a súa espera e confésalle estar tamén el agardando, máis, segundo as súas palabras, trátase a súa dunha espera "moi particular", pois rematará tan pronto como decida poñerlle fin; para ser exactos, non máis tarde das catro da mañá. Os dous parten xuntos cara a Times Square, se ben o narrador non ten a seguridade de teren chegado nunca ao seu destino.

Revelan seren estranxeiros, mais o Belga omite a súa orixe e o seu nome, afirmando só levar moitos anos vivindo como estranxeiro, selo sen referencia a ningún país concreto e considerar que unicamente podería vivir como tal. Inician unha conversa trivial na que intercambian unha serie de referencias históricas; porén, o Belga confesa que a única historia que realmente lle interesa é a súa propia, que é verdadeira, a diferenza da súa biografía.

O capítulo péchase co anuncio por parte do Belga do relato dunha "historia francamente interesante" na que entra en escena unha rapaza americana que coñecera nunha terminal de autobuses da cidade.

O segundo capítulo recolle a narración que o Belga fai da historia coa rapaza, da que, por mor da súa expresa aversión cara os antropónimos, evita dar o nome e á que se refire como "the girl" (no manuscrito, abreviado como "G."). Dáse conta dunha saída do Belga ao cine en compañía da rapaza e do Estudiante Yemení. Alúdese a manifestacións explícitas de interese por parte de G. cara ao Belga ante a aparente indiferenza do Estudiante Yemení. Regreso do cine e escenas eróticas, sen chegar a máis, entre G. e o Belga no apartamento da rapaza.

Prodúcese unha interrupción temporal da historia e fan a súa aparición no relato o Amigo Alemán e o Amigo Inglés, sobre os que o narrador ofrece algunhas pinceladas. Reanúdase a historia de G. Ao día seguinte o Belga volve ao seu apartamento e atópaa de conversa co Periodista Turco, quen, na súa opinión, tenta seducir á moza. O Periodista Turco abandona o lugar e prodúcese a primeira relación total entre $\mathrm{G}$. e o Belga. Referencias á inclinación de G. cara aos estranxeiros e ao foráneo, en oposición á postura do Amigo Inglés. Continúa o relato da historia de G. Unha tarde a rapaza confésalle que o Estudiante Yemení está fondamente namorado dela, mais que sabe con certeza que nunca poderá corresponder. Esta confesión provoca no Belga sentimentos de reprobación, tanto cara ao Estudiante Yemení, ao que cualifica como "monstro do disimulo" pola súa aparente indiferenza na escena do cine, como cara a G., pola crueldade de ter sometido ao Estudiante Yemení a esta malia ser coñecedora dos seus sentimentos cara a ela.

A historia chega á súa fin. Tal e como acordara coa moza o día anterior, o Belga diríxese cara ao apartamento de G., mais o Estudiante Yemení sáelle ao encontro e córtalle o paso alegando 
que a propia G. lle pedíu que lle dixese que estaba cansa e precisaba durmir, e que talvez puidesen verse ao día seguinte. O Belga desanda o seu camiño e, xa na rúa, deduce das palabras do Yemení que G. está co Periodista Turco, interpretando esta hipótese como unha vinganza do Estudiante Yemení cara el, quen, non podendo desprazalo directamente da súa posición privilexiada con respecto a G., determinaría facelo por medio do Periodista Turco. Porén, o Belga afirma que a vinganza nunca chegara a consumarse, xa que el non se considera vítima ao non sentir como unha derrota a caída de G. en mans do Periodista Turco.

O Belga conta a primeira parte da súa verdadeira historia. Aquela mesma tarde, de regreso á casa dende o apartamento de G., ten a sensación inequívoca de que todo o mundo é irreal: "Nada do que me rodea ten razón de ser, e o que non ten razón de ser non é, e non hai volta que darlle. Ó dicir que non é, quero dicir que se trata só de impresións falsas". Agás el mesmo, todo se reduciría impresións falsas, circunstancia que interpreta como resultado dun castigo do que di descoñecer tanto o responsable como o motivo.

O Belga anuncia o relato da segunda parte da súa historia, que, segundo di, é a espera á que se referira con anterioridade.

O terceiro capítulo ábrese coa dúbida do narrador sobre se el e o Belga terían chegado a Times Square. Prodúcese un brusco cambio de escenario, que o narrador acolle "con impasible naturalidade", e os personaxes aparecen nun novo marco "que non presentaba semellanza ningunha coa noite de Manhattan". Chegan a unha estación ferroviaria. Do seguinte lapso de tempo o narrador non conserva ningunha lembranza, e todo canto pode dicir é "que me atopei nun tren que viaxaba na noite a toda velocidade". Ambiente onírico e alucinado no departamento dun tren do que son os únicos ocupantes.

Chegan a unha estación deserta, saen ao exterior e camiñan por rúas intensamente iluminadas, mais carentes de calquera viandante e de tráfico rodado, aínda que profusamente dotadas de sinais de circulación. Entran nun edificio sen porteiro nin vixiante nocturno e chegan a unha sala de exposicións na que son os únicos visitantes.
Por sorte para o narrador, que confesa desexar en secreto "facer un alto nalgún sitio máis acolledor", os dous personaxes entran nun NightClub ("nunha especie de", precisa o narrador, coa súa xa habitual ambigüidade). O Belga inicia a súa teoría das "falsas impresións": "tódolos mitos, como tódalas lendas, coma toda a historia e tódolos escritores e pensadores do pasado e do presente son iso soamente, falsas impresións". A conversa é interrompida por unha das empregadas do local, que pouco despois realiza a súa actuación. Ao remate desta, o narrador decátase da ausencia do Belga e decide saír na súa procura. Durante o paseo, descobre que a cidade está na beiramar.

Atopa ao Belga nun peirao e achégase a el. Este explícalle que se foi alí foi por mor da súa espera, "para decidir non agardar máis": "Dentro de pouco, decidirei non agardar por máis tempo e o meu engano rematará. Desfareime de tódalas miñas impresións falsas". O narrador afirma non acabar de comprender o asunto da súa espera e inicia unha argumentación coa que tenta poñer de manifesto o absurdo da verdadeira historia do Belga. Canso ante a evidente imposibilidade de chegar a un acordo, o narrador pregúntalle se non lle gustaría comer algo. A resposta do Belga ("pulpo") supón un descubrimento para el, pois delata a súa verdadeira nacionalidade e pon de manifesto que son paisanos ("un dos rasgos máis típicos dos meus paisanos é o de considera-lo pulpo coma unha das comidas máis exquisitas, coma unha verdadeira regalía").

O Belga admite a súa orixe. O entusiamo do narrador, entregado a un verborreico monólogo patriota, contrasta coa frialdade do Belga, que comenta, cortante: "Deixei ese país ós vinteún anos, e non tiven endexamais o menor desexo de retornar a el e de vivir con aquela clase de xente". Prodúcense intres de tensión.

O narrador consulta o reloxo: faltan dez minutos para as catro, hora límite establecida polo Belga para a desaparición das súas impresións falsas. Porén, os acontecementos adiántanse, pois o narrador, tomado pola carraxe debido ao que considera unha resposta humillante, empuxa ao Belga facéndoo caer ao mar dende o peirao. Observa, a continuación, que "Nada pasou, á parte da súa caída, como, por outra parte, era de esperar". 
O narrador reemprende o seu camiñar pola cidade e, por azar, os seus pasos condúceno de novo á estación de ferrocarril. Alí atopa un tren agardando; sen dubidalo, sobe e acomódase nun departamento que lle parece o mesmo da viaxe de ida. Inicia unha serie de reflexións a propósito da posibilidade de apropiarse da verdadeira historia do Belga, para o cal abondaría con considerar a este como un simple mensaxeiro da súa verdadeira historia, pasando, deste xeito, a ocupar automáticamente el mesmo o papel de auténtica víctima das falsas impresións. Con todo, o narrador non considera seriamente a hipótese, senón que a concibe máis ben como un pasatempo ("Naturalmente, eu logo cansara do pasatempo de apropiarme da verdadeira historia do Belga").

O capítulo péchase cunha dúbida: “¿Falaría o Belga en serio?".

O capítulo cuarto iníciase co narrador espertando no seu hotel. Descrición da súa rutina diaria e algunhas consideracións sobre a cidade de Nova York. O narrador volve preguntarse se terían chegado a Times Square.

A xeito de peche, lánzase unha advertencia ao suposto destinatario do relato para que non caia na tentación de considerar este como un soño ou como resultado dos efectos do whisky trasfegado en compañía do seu vello amigo inmigrante.

No capítulo quinto, como se indicou, engadido con posterioridade, toma a voz o tradutor, segundo di, co obxectivo de aclarar os motivos que o levaron a cualificar de "repelentes" as ideas ideas recollidas no relato. Considera que cando o Belga di que nada de canto o rodea ten razón de ser quere dicir, en realidade, que nada satisfai o seu gusto na medida suficiente para que mereza ser. En consecuencia, pensa que, agás el mesmo, nada ao seu redor ten existencia real. O tradutor entende esta teoría das falsas impresións como unha "desprezativa negación do mundo" resultado dunha actitude "absolutamente desapegada", que "só pode se-lo froito dun total desarraigamento" e que "ben merece o calificativo de repelente para os que pensamos que o único valioso, importante e interesante é incuestinablemente a realidade".

Para rematar, o tradutor acaba concluíndo que o Belga ignora que un mundo á súa medida sería igualmente sorprendente e inxustificable que aquel do que el renega, pois inxustificable e gratuíto sería, ao seu xuízo, calquera outro mundo.

\section{A ANONIMIA DOS PERSONAXES}

Todos os personaxes de Cara a Times Square son individuos anónimos, cunha identidade persoal imprecisa, dos cales descoñecemos o nome e practicamente calquera información. Alúdese a eles facendo referencia á súa nacionalidade, real, ficticia ou presuposta, cunha soa excepción, de maneira que os xentilicios acadan a categoría de antropónimos, figurando, consecuentemente, escritos con maiúscula inicial.

Deste xeito, atopamos personaxes como "o Belga", ao que o narrador bautiza deste modo ["Chamareille desde agora o Belga (non vai tardar nada en sabe-la razón)"] por presupoñelle esta nacionalidade, se ben, confesa, sen demasiada convicción ("Sen saber moi ben por que, eu figureime de seguida que debía de ser belga ou algo polo estilo"). Fronte a esta asignación intuitiva de xentilicios identificadores, existen outros personaxes individualizados por medio dun xentilicio real, isto é, xustificado de acordo coa nacionalidade atribuída, non cuestionada en ningún momento na novela. É o caso do Periodista Turco e do Estudiante Yemení, aos que se chega a aludir, sen sombra de dúbida sobre a súa orixe, como "esta parella musulmana", indicando, ademais, en relación ao primeiro, que "O tema do seu monólogo era o seu país, Turquía", e, a propósito do Estudiante Yemení, que a súa ostensible tristura se atribuía ao "inevitable remate da súa estada en Norteamérica e á volta subseguinte para o seu país", ou "chegada ó Yemen".

Atopamos aínda exemplos do uso de xentilicios ficticios na novela, recoñecidos como tales por parte do narrador. É o caso do Amigo Alemán, do que, malia asignarlle este cualificativo, se aclara que "En realidade, el era norteamericano de nacemento. Pero tódolos seus devanceiros foran alemáns e o alemán era a súa fala familiar". En circunstancia semellante se atopa o personaxe do Amigo Inglés, que, en base ao seu fervente nacionalismo estadounidense, contrario a toda forma de interferencia estranxeira, presupoñemos norteamericano ("Refugaba violentamente o rock por razóns opostas ás de G. 
Para el constituía un ataque contra a xenuína tradición musical norteamericana, contra os enxebres folk-songs. Era unha manifestación máis das innúmeras influencias alleas (negras neste caso, afirmaba) que ameazaban o carácter nacional dos Estados Unidos. Tales influencias eran, segundo el, resultado de tódalas masas de inmigrantes ás que nunca se debera terlles permitido ingresar no país: xudeos, italianos, gregos, latinoamericanos, e, desde logo, negros", "El negaba ser racista, pois, segundo el dicía, só propugnaba o dereito de toda nación a manter intacta a súa propia personalidade e de protexela contra interferencias estranxeiras. Pero, por outra parte, sostiña cruamente que os negros debían ser devoltos a África" etc). O xentilicio co que se identifica ao Amigo Inglés, xustificaríase, ao noso ver, nunha suposta ascendencia británica que podería deducirse da seguinte afirmación: "En todo caso, o Amigo Inglés afirmaba que verdadeiramente norteamericanos érano só as persoas nadas nos Estados Unidos de devanceiros británicos ou dos países protestantes do norte de Europa".

A excepción nese proceso de individualización dos personaxes a través da asignación dun xentilicio caracterizador á que nos referíamos máis arriba está representada polo único personaxe feminino da obra, da que o narrador afirma descoñecer o nome e á que se alude como G., abreviatura de "the girl" ("o Belga nunca me dixo o nome da rapaza (...). Sempre aludía a ela chamándolle the girl, sen máis; así que eu, para abreviar, chamareille simplemente G.").

Esta omisión do nome dos personaxes é o mellor expoñente da procura da abstración e ambigüidade das que se pretende dotar a súa identidade e que, como foi sinalado por Franco Grande na introdución á obra da súa edición de $1989^{2}$, constitúe unha das notas predominantes da novela. $\mathrm{O}$ resultado son personaxes de identidade esluída, figuras concibidas, citando novamente a Franco Grande (p. 27), "en función do clímax da novela, que é un relato abstracto", que "Non pretenden, pois, ser persoas comprobables no mundo da realidade inmediata, senón pretextos nos que se asente aquela abstracción e que sirvan ás necesidades expresivas desa orde que o autor se propuxo".

Este receo cara os nomes propios plásmase tamén na novela en forma de fobia dun dos personaxes: "Pero é enormemente grande a cantidade de datos e feitos importantes con el relacionados que quedaron para sempre ignotos para min. Entre eles, algúns que, de ordinario, se comunican xa no mesmo intre de iniciar unha amistade. Por exemplo, o seu nome. O Belga detestaba os nomes propios. Sobre todo os persoais". E en relación a G.: "o Belga nunca me dixo o nome da rapaza; non é preciso repetir que aborrecía os nomes propios". Ademais de coa identidade persoal, nesta pasaxe establécese unha relación entre os antropónimos e a identidade nacional, advertindo que "Pode tamén que recease dicirme o seu nome por medo de que puidese deducir del a súa nacionalidade e deixase así de ser de ningures". O factor da anonimia non fai esvaecer, polo tanto, soamente a identidade persoal dos personaxes, mais tamén a nacional, facendo deles individuos desarraigados, desvencellados de todo lugar, ou, como chega a dicir o Belga en referencia a si mesmo, "estranxeiros sen referencia a ningún país concreto".

A animadversión deste personaxe cara os antropónimos vai máis alá da omisión do seu propio: o Belga refuga tamén coñecer o do narrador, desinteresándose del ("Así e todo, a verdade é que a ignorancia dos nosos nomes respectivos - por suposto, el nunca me preguntou a min polo meu- non volveu máis dificultoso o noso diálogo") e mesmo evitando lelo cando

\footnotetext{
2 “Cara a Times Square é unha das obras máis ambiguas da literatura galega. Penso que é a ambigüidade a súa nota máis desconcertante e, tamén, onde máis acertos expresivos logrou o autor. Porque nesta novela son ambiguos os seus personaxes (o Belga éo en grao sumo, o mesmo Narrador, ou o Estudiante Yemení, o Periodista Turco, etc.), ambigua é cada situación (a viaxe que o Narrador e o Belga fan en tren, a cidade desolada á que chegan, o Night Club no que recalan, a cidade pola que camiñan coma pantasmas, etc.); ambiguo, ó cabo, é o relato mesmo, todo el, coma se a intención do autor fose xustamente mantelo sempre nas desdebuxadas fronteiras entre a realidade e o soño" (1989: 31).
} 
este lle entrega unha tarxeta de visita ("deille unha tarxeta de visita que el revirou de inmediato como para fuxir da tentación de le-lo meu nome nela").

\section{A PERDA DA IDENTIDADE NA GRAN- DE URBE}

O aspecto da construción da anonimia vese favorecido pola localización espacial na que se desenvolve a historia, un escenario exterior integramente urbano (obviamos nesta análise os marcos espaciais do departamento do tren e do Night-Club) que actúa como factor coadxuvante nese obxectivo de diluír a identidade, tanto individual como nacional, dos personaxes.

Así, os tres escenarios exteriores nos que transcorren os feitos son espazos urbanos: a cidade onde o narrador e o Belga se atopan e inician o seu camiñar nocturno, o lugar a onde o Belga chega en compañía de G. e no que se desenvolve a súa historia coa rapaza, e a cidade na que o Belga e o narrador rematan despois de tomar un tren do que semellan ser os únicos ocupantes.

En relación ao primeiro destes tres escenarios, o único identificado e identificable cunha localización real, dende moi cedo sabemos que se trata da cidade de Nova York: "Eu, pola miña parte, durante a miña estada en New York, case non deixaba pasar nin un só día sen coller un autobús para o Village". Con todo, unha referencia a este barrio neoiorquino de Greenwich Village ("Eu pasara aquela tarde bebendo whisky en diferentes bares do Greenwich Village"), unhas liñas máis arriba, delataría, a ollos dun lector informado, a localización espacial da historia cun chisco máis de antelación. Este tipo de referencias son frecuentes nesta primeira parte do relato e, así, atopamos intercalados na narración nomes de célebres prazas, distritos e rúas, ou de edificios emblemáticos (Washington Square, Times Square; Manhattan; Broadway central; New York Public Library, Port Authority Bus Terminal, edificio do Times (The New York Times)).

Para máis seguridade de que o lector non perde a perspectiva de atoparse ante un espazo urbano, aparecen, tamén diseminadas ao longo do relato, distintas referencias urbanísticas que remiten a este tipo de escenario: "Metinme por rúas case desertas", "resolvín determe diante dunha parada de autobús", "Principiei a andar pola acera", "a noite por alí era francamente escura, pese ás luces públicas".

Por se este tipo de indicacións non fosen suficientes e o lector puidese aínda perder a conciencia da natureza do escenario ou non alcanzase a comprender a súa magnitude, o narrador incide sobre este aspecto coa seguinte reflexión: "Aquí estamos, no miolo da meirande metrópolis do mundo". Comentario semellante se rexistra un pouco máis adiante, desta volta, de boca do Belga. Referíndose á animadversión do Amigo Inglés por Nova York, alude á cidade nos mesmos termos: "Curioso, ¿non é verdade?, estar tan cerca, relativamente, da meirande metrópole do mundo e non ter ido a ela nin para unha visita dun día".

$\mathrm{O}$ segundo dos espazos exteriores nos que se desenvolve o relato, aquel a onde o Belga chega acompañando a G. e no que ten lugar a súa historia coa rapaza, non é, a diferenza do anterior, un escenario identificado, polo menos explícitamente para o lector. A razón desta puntualización atopámola en certas referencias onomásticas (Thornden Park) e nas palabras do narrador, que, nunha interrupción ao relato do Belga, indica que, se ben este "nunca mencionou o nome da cidade mesma", "Non é difícil averiguar cal era, e coido que eu o averigüei; pero non cho vou revelar, porque seguramente ó Belga non lle gustaría". Con todo, se algo fica claro é que se trata novamente dun escenario urbano, pois alúdese repetidamente a este tipo de localización: "O Estudiante Yemení preguntoume tamén se pensaba estar na cidade por moito tempo", "ó Belga deberon de parecerle chocantes os nomes das rúas daquela cidade", "Así e todo, nunca mencionou o nome da cidade mesma", etc.

O derradeiro dos espazos exteriores nos que transcorre a novela está representado polo lugar ao que o narrador e o Belga chegan tras a súa viaxe no tren. Trátase novamente dun escenario descoñecido, mais reiteradamente caracterizado como urbano: "Polo que puidera ver ata entón, tódalas rúas da cidade compartían esta circunstancia", "Percorrín toda a parte central da cidade e seguramente andei máis dunha vez pola mesma rúa, porque descoñecía por completo a estructura xeral da cidade", "Eu non imaxinaba que a cidade puidese estar na beiramar", etc. Esta ambientación urbana sublíñase botando 
man novamente do recurso das referencias a elementos urbanísticos, e, neste caso, tamén do tráfico: "Desembocamos nunha avenida longa, ancha e recta", "tódalas rúas da cidade compartían esta circunstancia: estaban deslumbrantes, inundadas de luz pública", "Pouco importaba que algunhas fosen realmente avenidas, mentres que outras non pasasen de calexas estreitas; o caso é que todas moi ben poderían representarse por unha rúa recta, longa e deserta, cunha sucesión sen fin de farois ás dúas beiras", etc.; "Mais de súpeto decateime doutra circunstancia aínda máis chocante: a ausencia de tráfico rodado", "Si, as rúas estaban baleiras, sen coches nin autobuses, sen ningunha clase de transporte, público ou privado. Pero, curiosamente, había profusión de sinais de tráfico axeitadamente distribuídos".

\section{O PROTAGONISMO DO TEMA DA ES- TRANXEIRÍA}

O tema do inmigrante e da estranxeiría é un aspecto de especial protagonismo na novela, recorrente, en distintas formas e voces, ao longo da narración. Atópase fortemente vencellado ao asunto da identidade e vese propiciado pola ambientación urbana da historia, e, en particular, pola escolla como escenario da cosmopolita metrópole de Nova York.

Así, xa dende as primeiras liñas o narrador se identifica como un inmigrante que se move en ambientes que lle son afíns: "Eu pasara aquela tarde bebendo whisky en diferentes bares do Greenwich Village cun vello inmigrante amigo meu. Os dous eramos do mesmo país - un deses pequenos e desgraciados países que levan séculos desangrándose, vertendo ríos de emigrantes nos portos americanos"; "O dono do derradeiro bar onde tomaramos uns whiskies era tamén un vello inmigrante, un veterano camarada, por así dicilo, do meu amigo, e paisano de nosóutro-los dous".

Estranxeiro é tamén o Belga, se ben este enigmático personaxe se amosa reacio a falar sobre o tema, admitindo soamente levar moitos anos vivindo como tal e selo sen referencia a ningún país concreto. Evita dar calquera outra información sobre a súa orixe, polo que, como vimos, o xentilicio identificador que se lle aplica non responde máis que a meras conxecturas do narrador: "Explicoume que levaba moitos anos vivindo como estranxeiro. Máis aínda: pensaba que só podía vivir como estranxeiro", "Eu son estranxeiro sen referencia a ningún país concreto. (...) Así que non me preguntes pola miña nacionalidade, porque eu son realmente de ningures".

Á nómina de personaxes estranxeiros que participan na historia habería que engadir aínda outros dous: o Estudiante Yemení e o Periodista Turco. As excepcións neste sentido estarían representadas por G., o Amigo Alemán e o Amigo Inglés (se ben o xentilicio identificador destes últimos delata a súa procedencia de familias inmigrantes).

$\mathrm{O}$ aspecto da estranxeiría, a condición de inmigrantes destes personaxes, é un trazo ao que se lle concede capital importancia na novela, ata o punto de que, como sinalabamos en apartados anteriores, acada a categoría de trazo identitario e identificador fundamental duns personaxes anónimos sobre os que se nos ofrece moi escasa información.

Aprézase unha clara vontade por parte do autor de destacar a multiculturalidade dos escenarios nos que se desenvolve a historia, e, en particular, da cidade de Nova York. Así, alén da comparecencia no relato destes personaxes de orixe foránea, son reitaradas ao longo da narración as referencias á cidade como destino de grandes fluxos migratorios e ás distintas comunidades de inmigrantes alí establecidas: "falaron de vagar, o meu amigo e mais el, de lembranzas comúns e, sobre todo, da situación actual, feliz ou non, doutros paisanos, vellos coma eles ou máis novos, e camaradas deles tamén na dura aventura da inmigración -a miúdo ilegal- nos Estados Unidos"; "O que quería dicir era que, a pesar de toda a enorme masa heteroxénea dos seu novos inmigrantes, New York, polo seu carácter, non difería moito, no seu ver, do carácter dos países do norte de Europa de fondo protestante; "Longas rúas de negros, abundancia de comunidades gregas e xudeas, e por obra da universidade, exóticos tipos de Asia e África. E tamén grande presencia de estudiantes latinoamericanos".

Outra das formas baixo as que se aborda o tema da estranxeiría na obra é a filia do personaxe de G. cara os estranxeiros e, en xeral, cara todo o foráneo: "quérolle a esta casa porque me 
deu a oportunidade de coñecer a unha chea de estranxeiros, algún deles moi, moi interesantes", "G., por exemplo, (...), tornáralle as costas [ao rock] porque tiña un sabor demasiado norteamericano para o seu presente gusto estranxeirizante", etc. Esta súpeta inclinación cara o foráneo sería, segundo a rapaza, produto da influencia exercida por unha das súas lecturas, explicación que, porén, non remata de convencer ao Belga, quen só a admite parcialmente: "Durante a viaxe, ela díxome que acababa de ler ese libro, The Ugly American, e que a impresionara moi fondamente. (...) A principal lección que sacara era que os norteamericanos deberían ser moito máis afables cos estranxeiros, se querían mellorar a súa imaxe no mundo"; "eu sei moi ben que, fose cal fose a versión da rapa$\mathrm{za}$, as principais influencias sobre a súa conduta eran máis complicadas cá simple lectura de The Ugly American".

No extremo oposto a G. atopamos ao Amigo Inglés, que aparece caracterizado como un individuo marcadamente xenófobo e contrario a calquera influencia externa na cultura norteamericana (para a caracterización do personaxe, véxase o apartado 3).

Finalmente, destacaremos a reflexión que sobre a relación entre inmigración e confusión / carencia de identidade nacional fai o narrador no contexto dunha conversa co Belga a propósito da cidade de Nova York (aspecto en relación ao cal, este último, "estranxeiro sen referencia a ningún país concreto", constituiría o máximo expoñente): "Agora ben, ¿Que significaba exactamente ser norteamericano? ¿Eran os polacos, os gregos, os italianos establecidos en Estados Unidos auténticos americanos? ¿E os negros? ¿E os portorriqueños?”.

\section{PECHE}

A xeito de síntese do exposto ao longo deste traballo, podemos afirmar que a construción da identidade, tanto persoal como nacional, dos personaxes de Cara a Times Square responde á ambigüidade característica da obra. Atopámonos, así, perante figuras anónimas, cunha identidade persoal difusa, que aparecen individualizadas, maioritariamente, por medio de xentilicios reais, ficticios ou presupostos. Esta anonimia dos personaxes redunda, paralelamente, en certos casos, nunha ocultación da súa identidade nacional, e vese favorecida pola ambientación urbana da historia. Así mesmo, o escenario urbano, marcadamente multicultural, no que se moven os personaxes incide na súa identidade nacional, promovendo a confusión, solapamento ou disolución desta.

\section{REFERENCIAS BIBLIOGRÁFICAS}

ForCadela, Manuel (1993): Manual e escolma da Nova Narrativa Galega. Santiago de Compostela: Sotelo Branco.

Gonsar, Camilo (1989): Cara a Times Square (ed. Xosé Luís Franco Grande). Vigo: Xerais. Noia Campos, María Camino (1992): A Nova Narrativa Galega. Vigo: Galaxia.

TARRIO, Anxo (1994): Literatura galega: aportacións a unha historia crítica. Vigo: Xerais. VILAVEDRA, Dolores (1999): Historia da Literatura Galega. Vigo: Galaxia. 